\title{
Luminance Compensation based on Background Shadow for White-Pill Identification
}

\author{
Somchart Chokchaitam ${ }^{1}$, Phakdee Sukpornsawan ${ }^{2}$
}

\begin{abstract}
Pill color is applied as one of important features for pill identification; however, most of pill color is white. It's difficult to classify two similar white pills because pill's color is sensitive to luminance intensity. To reduce its luminance-intensity effect, RGB color is converted in term of YUV component because when its luminance intensity is increased, only its $Y$ value is increased but its $U$ and $V$ values are almost constant. Therefore, its $U$ and $V$ values can be directly applied for image recognition. In this report, we propose luminance compensation based on background shadow to compensate luminance-intensity effect in $Y$ value. When its luminance intensity is increased, $Y$ value of background is also increased but $Y$ value of pill shadow is slightly decreased. Therefore, difference between $Y$ value of background and its shadow is effectively applied for luminance compensation. Experimental results confirm an effectiveness of our proposed compensation method.
\end{abstract}

Keyword-Pill Identification, Shadow background, Luminance compensation, Digital image recognition, YUV

\section{Introduction}

Pill errors may generate additional serious health problems to patient. There are many error causes such as the wrong pill, misunderstanding prescription, incorrect instruction to the patients and etc. To avoid pill confusions and mistakes, digital image recognition are applied for pill identifications. There are many important image features used for image recognition such as its imprint, shape, size and color. Color feature is not easy to directly identify from pill image because pill colors are depended on lighting condition. For example, if luminance intensity is increased, all RGB values of the selected pill are also increased.

However, if we convert its RGB components into YUV components, we find that the $Y$ value is significantly changed but the $\mathrm{U}$ and $\mathrm{V}$ values are almost constant. This is because the $\mathrm{U}$ and $\mathrm{V}$ values represent color tone of the selected object that aren't sensitive to its luminance intensity; whereas, the $\mathrm{Y}$ value is sensitive to its luminance intensity. Therefore, its $\mathrm{U}$ and $\mathrm{V}$ values can be directly applied for image recognition.
In this report, we propose luminance compensation based on background shadow to reduce luminanceintensity effect in $\mathrm{Y}$ value of the selected pill. When its luminance intensity is increased, $Y$ value of background is also increased but $\mathrm{Y}$ value of pill shadow is slightly decreased. Therefore, we can apply relation between the Y value of the selected pill and the difference between $\mathrm{Y}$ value of background and its shadow used for luminance compensation.

In our experiment, two similar white pills, Motilium-M and Buscopan, are recorded by normal iphone6 with normal white A4-paper background under various luminance intensity. We find relation between the $\mathrm{Y}$ value of the selected pill and difference between $Y$ values of background and its shadow. Experimental results confirm an effectiveness of our proposed compensation method.

\section{Basic Pill Identification}

In General, commercial pill must have unique combined feature for easy identification in terms of imprint, shape, size and color of the pill. Therefore, there are some pill-identification applications using keywordsbased pill identification tools. The keywords as in [1] are based on imprint, shape, size and color of the pill.

\section{A. Imprint feature}

Imprints appearing on the pill can be a symbol, text, a set of digits, or any combination of them. The imprint feature is unique but some pill doesn't have imprint. Therefore, pill identification must use the other features instead. Figure 1 illustrates examples of pill imprints.

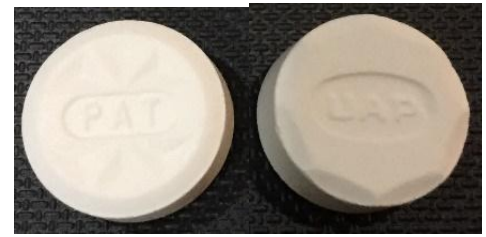

Figure 1. Examples of pill imprints 


\section{B. Shape feature}

Shape feature is one important feature for pill identification. Normally, shapes of the pill are classified to oblong, round, 3 sided, square, rectangle, diamond, 5 sided, 6 sided, 8 sided and etc. Figure 2 illustrates examples of pill shapes.

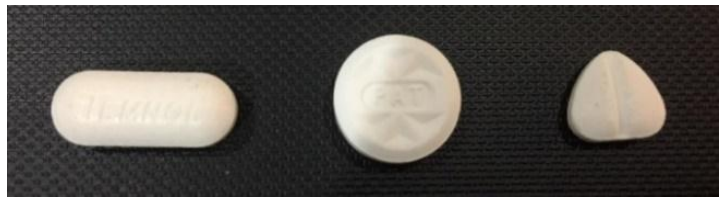

Figure 2 Examples of pill shapes

\section{Size feature}

Normally, Size of pill can be applied for pill identification in terms of small, medium or large sizes. However, if digital image processing is applied to pill image, pill size will be more useful for pill identification.

\section{Color feature}

There are many pill colors such as black, blue, brown, gray, green, orange, peach , pink, purple, red, tan, yellow, and white. However, white color is the most popular color for pill, but white color is generally classified into only 3 white-color shades as in [2] and [3]; white, clear and off white. However, there are many white-color shades in white pills.

Figure 3 illustrates an example of two similar white pills that have problem to clarify the difference of the pill color. This is because when luminance intensity is increased, all RGB values of the selected pill are also increased. In this report, we propose luminance compensation based on background shadow to compensate luminance-intensity effect in Y value applied for white pill identification.

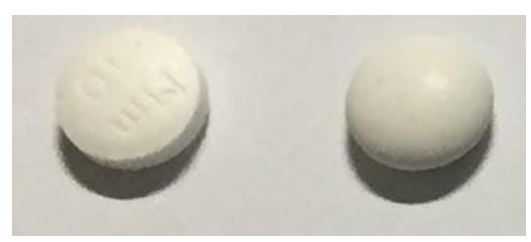

Figure 3 Examples of two similar white pills (Motilium-M and Buscopan)

\section{Color Features for White Pills}

\section{A. RGB of White Pills}

There are many kind of white-pill shades. Moreover, when light luminance intensity is changed, RGB of white pills are all changed. Therefore, RGB is not suitable directly applying for pill identification. Table 1 illustrates
RGB of three similar white pills under various luminance intensity. In each pill image, average of RGB is calculated to represented color of the selected pill. Since luminance intensity is changed, $R_{\max }$ may mean average of $R$ value of the selected pill under high luminance intensity.

Table 1 RGB of three similar white pills

\begin{tabular}{|l|l|r|l|}
\hline RGB $\backslash$ pill & Anamai & Motilium-M & Buscopan \\
\hline $\mathrm{R}_{\min } / \mathrm{R}_{\max }$ & $239 / 250$ & $212 / 229$ & $192 / 214$ \\
\hline $\mathrm{G}_{\min } / \mathrm{G}_{\max }$ & $228 / 239$ & $205 / 223$ & $187 / 207$ \\
\hline $\mathrm{B}_{\min } / \mathrm{B}_{\max }$ & $207 / 216$ & $184 / 203$ & $166 / 187$ \\
\hline
\end{tabular}

\section{B. RGB to YUV transform}

In this report, RGB components are transformed into YUV components [4-5] to reduce luminance-intensity effect. YUV component is calculated from the following equations

$$
\begin{aligned}
& \mathrm{Y}=0.299 * \mathrm{R}+0.587 * \mathrm{G}+0.114 * \mathrm{~B} \\
& \mathrm{U}=-0.147 * \mathrm{R}-0.289 * \mathrm{G}+0.436 * \mathrm{~B} \\
& \mathrm{~V}=0.615 * \mathrm{R}-0.515 * \mathrm{G}-0.100 * \mathrm{~B}
\end{aligned}
$$

where the R, G, B illustrate red value, green value, and blue value of the selected pill, respectively. The Y, U, V illustrate Luma value, Chrominance (U) value, and Chrominance (V) value of the selected pill, respectively. $\mathrm{Y}$ value is sensitive to light condition but $\mathrm{U}$ value and $\mathrm{V}$ value is less sensitive. Therefore, $\mathrm{U}$ value and $\mathrm{V}$ value is popular to directly apply for pill identification.

Table 2 illustrates YUV of three similar white pills under various luminance intensity. Figure 4 illustrates how $\mathrm{Y}$ value of the selected pill is sensitive to light condition. Figure 5 illustrates $\mathrm{U}$ and $\mathrm{V}$ value of the selected pill under various light condition. In figure 5, the ' $\mathrm{o}$ ' and ' + ' represent $\mathrm{U}$ value and $\mathrm{V}$ value, respectively. The $\mathrm{U}$ and $\mathrm{V}$ value is almost constant when luminance intensity is changed.

Table 2 YUV of three similar white pills

\begin{tabular}{|l|c|c|c|}
\hline YUV \pill & Anamai & Motilium-M & Buscopan \\
\hline $\mathrm{Y}_{\min } / \mathrm{Y}_{\max }$ & $229 / 240$ & $205 / 223$ & $187 / 207$ \\
\hline $\mathrm{U}_{\min } / \mathrm{U}_{\max }$ & $-13 /-10$ & $-12 /-9$ & $-10 /-7$ \\
\hline $\mathrm{V}_{\min } / \mathrm{V}_{\max }$ & $8 / 11$ & $4 / 8$ & $3 / 6$ \\
\hline
\end{tabular}




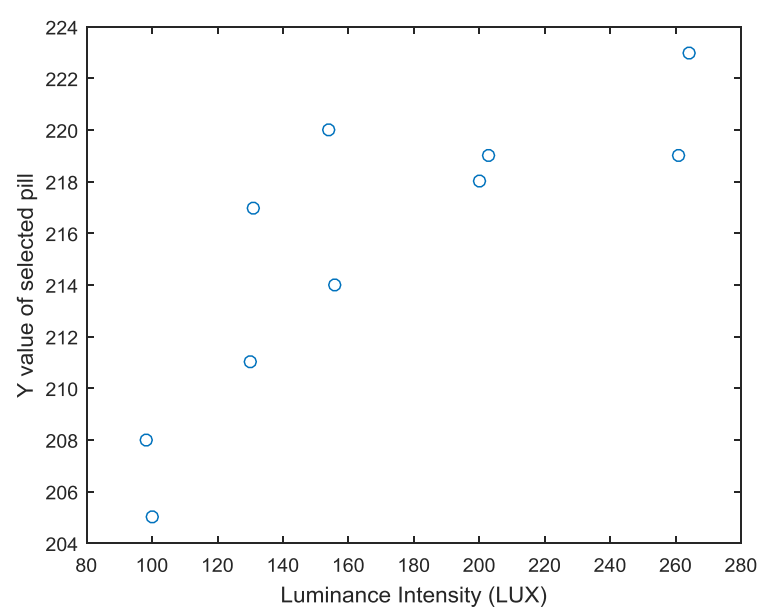

Figure $4 \mathrm{Y}$ value of the selected pill under various luminance intensity

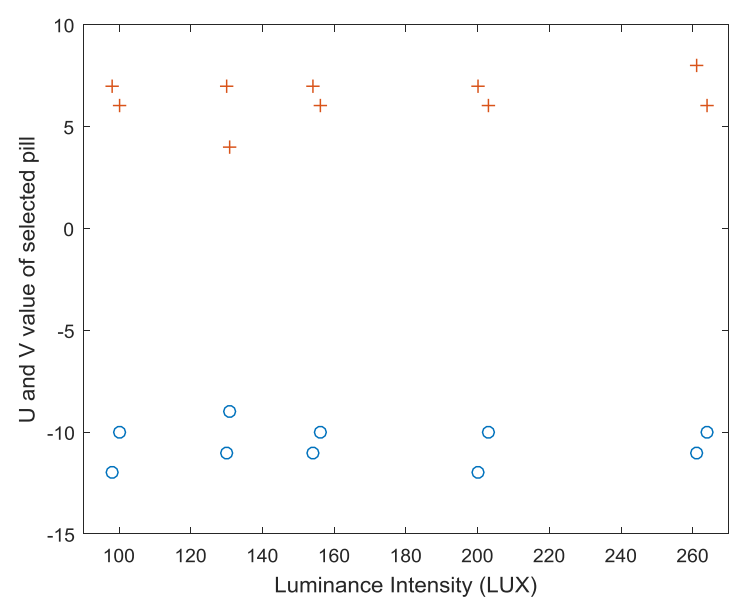

Figure $5 \mathrm{U}$ and $\mathrm{V}$ value of the selected pill under various luminance intensity

\section{Proposed Luminance Compensation}

\section{A. Shadow and Background}

Since $\mathrm{Y}$ value of selected pill is sensitive to luminance intensity [6], it's some problem to apply Y value for pill identification when light condition is uncontrollable. However, the shadow of the selected pill and background are also sensitive to luminance intensity.

Figure 6 illustrates $\mathrm{Y}$ value of shadow ('o') and Y value of background ('+') when luminance intensity is changed. When luminance intensity is increased, Y value of shadow is decreased but $\mathrm{Y}$ value of background is increased. Therefore, $\mathrm{Y}$ value of shadow and background can apply to reduce luminance-intensity effect in next section.

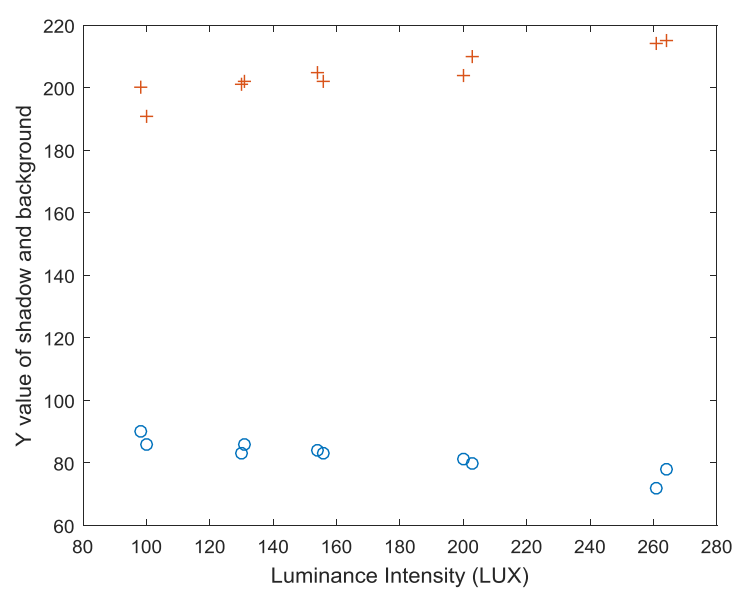

Figure $6 \mathrm{Y}$ value of shadow and background under various luminance intensity

\section{B. Relation between $Y$ value of the selected pill and $Y$ value of difference between shadow and background}

The Y values of selected pill, shadow and background are all sensitive to luminance intensity. When luminance intensity is increased, $\mathrm{Y}$ value of the selected pill is increased and $\mathrm{Y}$ value of difference between shadow and background is also increased. Figure 7 plots relation between Y value of the selected pill ('o' for Motilium-M and ' + ' for Buscopan) and Y value of difference between shadow and background. Then, we find an approximated equation between them as the follows

$$
\Delta \mathrm{Y}_{\mathrm{p}}=0.45^{*} \Delta\left(\mathrm{Y}_{\mathrm{b}}-\mathrm{Y}_{\mathrm{s}}\right)
$$

The $Y_{p}, Y_{b}$ and $Y_{s}$ illustrate $Y$ value of the selected pill, background and shadow, respectively.

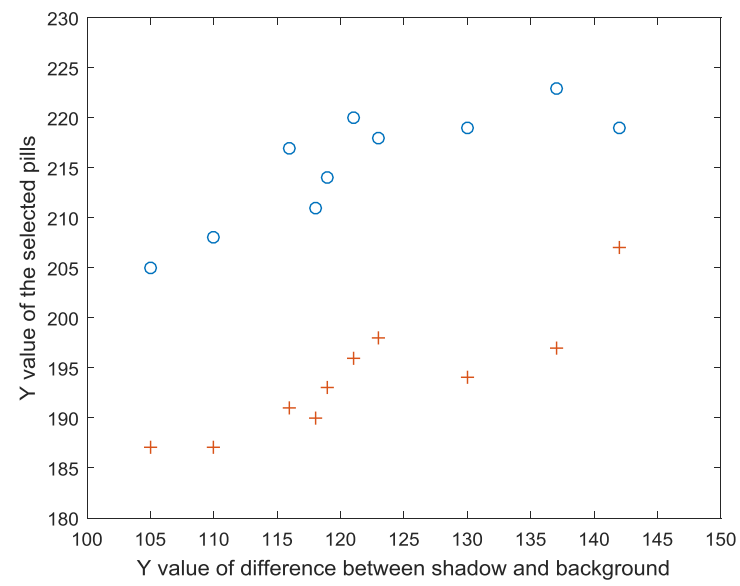

Figure 7 Relation between $\mathrm{Y}$ value of the selected pill and $\mathrm{Y}$ value of difference between shadow and background 
Proc. of the Sixth Intl. Conf. Advances in Bio-Informatics, Bio-Technology and Environmental Engineering- ABBE 2018 Copyright (C) Institute of Research Engineers and Doctors, USA. All rights reserved.

ISBN: 978-1-63248-148-1 doi: 10.15224/978-1-63248-148-1-09

\section{Proposed Luminance Compensation}

From equation (4), we propose an approximated equation between $\mathrm{Y}$ value of selected pill and difference between $\mathrm{Y}$ values of background and shadow

$$
\mathrm{Y}_{\mathrm{a}}=\mathrm{Y}_{\mathrm{p}}+65-0.45 *\left(\mathrm{Y}_{\mathrm{b}}-\mathrm{Y}_{\mathrm{s}}\right)
$$

The $Y_{a}, Y_{p}, Y_{b}$ and $Y_{s}$ illustrate $Y$ values of adjusted pill, original pill, background and shadow, respectively.

\section{Experimental Results}

In this report, we selected two similar white pills: Motilium-M and Buscopan as illustrated in figure 8. The light is generated from left side above of pill (above 30-35 degress). The pill images are taken from normal iphone6 under various luminance intensity. Yokogawa illuminance meter model 51002 is used to measure luminance intensity in this report.

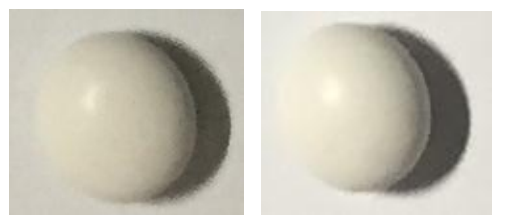

Figure 8 Buscopan taken under different luminance intensities

Table 3 illustrates RGB of Motilium-M, and its background and shadow, whereas, table 4 illustrates those of Buscopan. Table 5 and table 6 illustrate YUV of Motilium-M (after adjusted Y) and YUV of Buscopan (after adjusted $\mathrm{Y}$ ), respectively. From table 5 and $6, \mathrm{U}$ and $\mathrm{V}$ values of both Motilium-M and Buscopan are almost the same but $\mathrm{Y}$ value of original pill is depended on luminance intensity. After luminance compensation is applied, Y value of adjusted pill is less sensitive as illustrated in table 5 and 6.

Figure 9 illustrates $\mathrm{Y}$ value of Buscopan under various luminance intensity where ' + ' is for original image and ' $\mathrm{o}$ ' is for adjusted image. An effectiveness of our proposed method is confirmed since $\mathrm{Y}$ value of adjusted image is almost constant.

Figure 10 illustrates $\mathrm{Y}$ value (after adjusted) and $\mathrm{U}$ value of the selected pills ('o' for Motilium-M and '+' for Buscopan). Therefore, two similar white-shade pill can be identified using $\mathrm{Y}$ value (after adjusted) and $\mathrm{U}$ value.
Table 3 RGB of Motilium-M, and its background and shadow

\begin{tabular}{|c|c|c|c|c|c|}
\hline \multirow{2}{*}{$\begin{array}{c}\text { Lum. } \\
\text { Intensity } \\
(\mathbf{L U X})\end{array}$} & \multicolumn{3}{|c|}{ Selected Pill } & \multicolumn{2}{c|}{ Y value of } \\
\cline { 2 - 6 } & $\mathbf{R}$ & $\mathbf{G}$ & $\mathbf{B}$ & Shadow & BG \\
\hline 98 & 216 & 208 & 184 & 90 & 200 \\
\hline 100 & 212 & 205 & 185 & 86 & 191 \\
\hline 130 & 219 & 211 & 189 & 83 & 201 \\
\hline 131 & 222 & 218 & 198 & 86 & 202 \\
\hline 154 & 227 & 220 & 198 & 84 & 205 \\
\hline 156 & 221 & 215 & 194 & 83 & 202 \\
\hline 200 & 226 & 218 & 194 & 81 & 204 \\
\hline 203 & 225 & 219 & 199 & 80 & 210 \\
\hline 261 & 229 & 219 & 197 & 72 & 214 \\
\hline 264 & 229 & 223 & 203 & 78 & 215 \\
\hline
\end{tabular}

Table 4 RGB of Buscopan and its background and shadow

\begin{tabular}{|c|c|c|c|c|c|}
\hline \multirow{2}{*}{$\begin{array}{c}\text { Lum. } \\
\text { Intensity } \\
(\text { LUX) }\end{array}$} & \multicolumn{3}{|c|}{ Selected Pill } & \multicolumn{2}{c|}{ Y value of } \\
\cline { 2 - 6 } & $\mathbf{R}$ & $\mathbf{G}$ & $\mathbf{B}$ & Shadow & BG \\
\hline 98 & 194 & 188 & 166 & 90 & 200 \\
\hline 100 & 192 & 187 & 170 & 86 & 191 \\
\hline 130 & 196 & 190 & 170 & 83 & 201 \\
\hline 131 & 195 & 192 & 177 & 86 & 202 \\
\hline 154 & 202 & 197 & 177 & 84 & 205 \\
\hline 156 & 199 & 194 & 174 & 83 & 202 \\
\hline 200 & 205 & 199 & 177 & 81 & 204 \\
\hline 203 & 200 & 195 & 177 & 80 & 210 \\
\hline 261 & 214 & 207 & 187 & 72 & 214 \\
\hline 264 & 203 & 198 & 180 & 78 & 215 \\
\hline
\end{tabular}

Table 5 YUV of Motilium-M (after adjusted Y)

\begin{tabular}{|c|c|c|r|r|c|}
\hline \multirow{2}{*}{$\begin{array}{c}\text { Lum. } \\
\text { Intensity } \\
(\mathbf{L U X})\end{array}$} & \multicolumn{3}{|c|}{ Selected Pill } & \multirow{2}{*}{ Diff Y } & Adj Y \\
\cline { 2 - 4 } & $\mathbf{Y}$ & $\mathbf{U}$ & $\mathbf{V}$ & & \\
\hline 98 & 208 & -12 & 7 & 110 & 224 \\
\hline 100 & 205 & -10 & 6 & 105 & 223 \\
\hline 130 & 211 & -11 & 7 & 118 & 223 \\
\hline 131 & 217 & -9 & 4 & 116 & 230 \\
\hline 154 & 220 & -11 & 7 & 121 & 231 \\
\hline 156 & 214 & -10 & 6 & 119 & 225 \\
\hline 200 & 218 & -12 & 7 & 123 & 228 \\
\hline 203 & 219 & -10 & 6 & 130 & 226 \\
\hline 261 & 219 & -11 & 8 & 142 & 220 \\
\hline 264 & 223 & -10 & 6 & 137 & 226 \\
\hline
\end{tabular}


Proc. of the Sixth Intl. Conf. Advances in Bio-Informatics, Bio-Technology and Environmental Engineering- ABBE 2018 Copyright (C) Institute of Research Engineers and Doctors, USA. All rights reserved.

ISBN: 978-1-63248-148-1 doi: 10.15224/978-1-63248-148-1-09

Table 6 YUV of Buscopan (after adjusted Y)

\begin{tabular}{|c|c|c|c|c|c|}
\hline \multirow{2}{*}{$\begin{array}{c}\text { Lum. } \\
\text { Intensity } \\
(\text { LUX) }\end{array}$} & \multicolumn{3}{|c|}{ Selected Pill } & \multirow{2}{*}{ Diff Y } & Adj Y \\
\cline { 2 - 4 } & $\mathbf{Y}$ & $\mathbf{U}$ & $\mathbf{V}$ & & \\
\hline 98 & 187 & -10 & 6 & 110 & 203 \\
\hline 100 & 187 & -8 & 5 & 105 & 205 \\
\hline 130 & 190 & -10 & 6 & 118 & 202 \\
\hline 131 & 191 & -7 & 3 & 116 & 204 \\
\hline 154 & 196 & -9 & 5 & 121 & 207 \\
\hline 156 & 193 & -9 & 5 & 119 & 204 \\
\hline 200 & 198 & -10 & 6 & 123 & 208 \\
\hline 203 & 194 & -9 & 5 & 130 & 201 \\
\hline 261 & 207 & -10 & 6 & 142 & 208 \\
\hline 264 & 197 & -9 & 5 & 137 & 200 \\
\hline
\end{tabular}

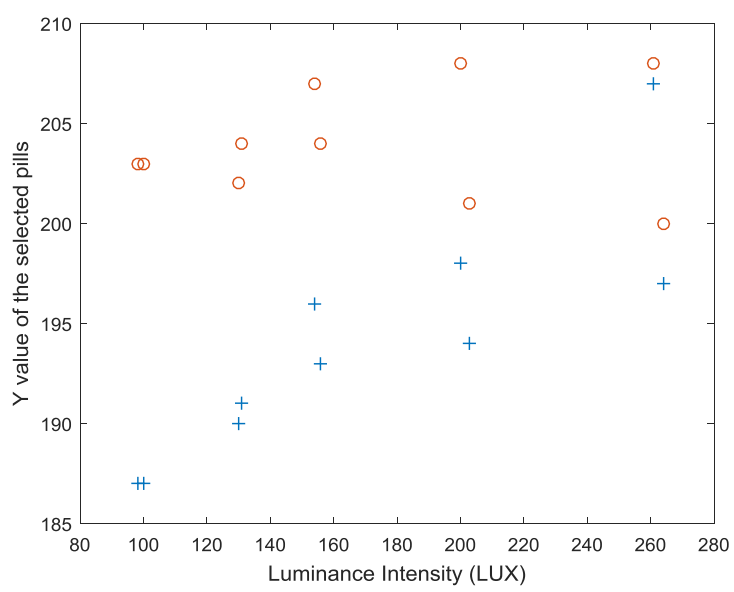

Figure 9 Y value (after adjusted) of the selected pill under various luminance intensity

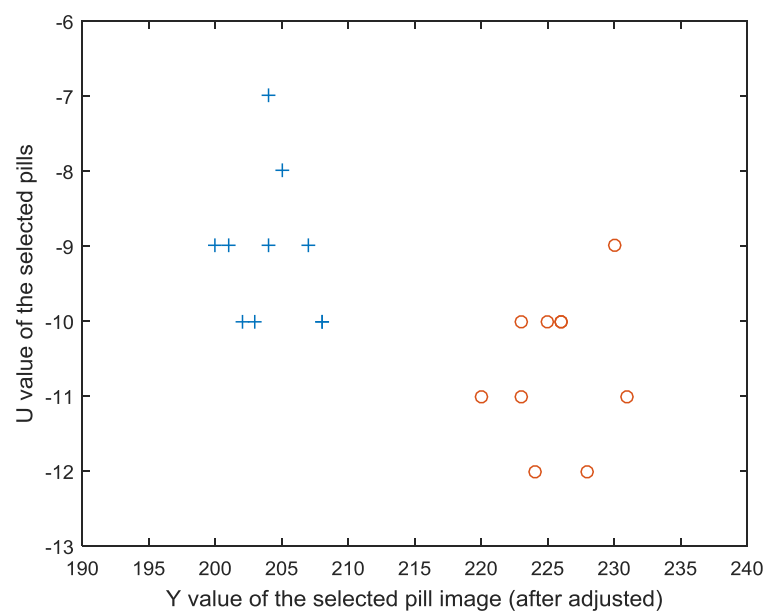

Figure $10 \mathrm{Y}$ value (after adjusted) and $\mathrm{U}$ value of the selected pill

\section{Conclusion}

In this report, we proposed luminance compensation based on background shadow to compensate luminance- intensity effect in $\mathrm{Y}$ value. The difference between $\mathrm{Y}$ value of background and its shadow is effectively applied for luminance compensation. Experimental results confirm an effectiveness of our proposed compensation method.

\section{Acknowledgement}

We would like to thanks National Research Council of Thailand (NRCT) for financially supporting this research

\section{References}

[1] Young-Beom L., Unsang P., Anil K. J., and Seong-Whan L.,"Pill-ID: Matching and retrieval of drug pill images", Pattern recognition Latters, 33 (2012) pp. 904-910

[2] Mahnke, Frank H, "Color, Environment, and Human Response", John Wiley \& Sons, pp. 80. Retrieved 17 December 2010

[3] Sickler, Dean, (2010)“The Keys to Color: A Decorator's Handbook", pp 11, Retrieved 17 December 2010

[4] Gupta G.S., Bailey D., "Discrete YUV look-up tables for fast color segmentation for robotic applications, Camadian conference on Electrical and Computer Engineering, 4564679, pp. 963-968, 2008

[5] Zhu H., Zhou S., Wang J., and Yin Z., An algorithm of pornographic image detection", Proceeding of the $4^{\text {th }}$ international conference on Image and Graphics, ICIG 2007, pp. 801-804, 2007

[6] Nguyen R.M.H., Kim S.J., and Brown M.S., "Illuminant aware Gamut-Based Color Transfer”, Pacific Graphic 2014, vol 33, no.7, 2014

\section{About Authors}

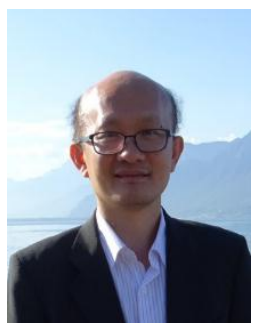

Somchart Chokchaitam received Dr. Eng. Degree in Electrical. Engineering from Nagaoka University of Tech. in 2002. He joined Thammasat university, Thailand as a faculty member since 1991 . He is an Assoc. Prof. at department of Elec. Eng. Thammasat university, Thailand. His current research interests are digital image processing for medicine.

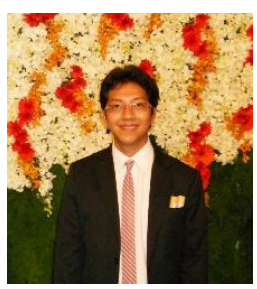

Phakdee Sukpornsawan received Master Degree in Biomedical Instrumentation. From Mahidol university in 2012. He joined Burapha university, Thailand as a faculty member since 2012. He is a student in medical Eng. Program, Thammasat university, Thailand. His current research interests are drug information and medicine image processing. 